\title{
Non-Infectious Cystitis
}

National Cancer Institute

\section{Source}

National Cancer Institute. Non-Infectious Cystitis. NCI Thesaurus. Code C78250.

An inflammation of the bladder which is not caused by an infection of the urinary tract.

Representative examples include interstitial cystitis and radiation-induced cystitis. 